\title{
Enrolee outcomes after health insurance plan terminations: a diagnosis of default effects
}

\author{
ANNA D. SINAIKO \\ Harvard University, MA, USA \\ RICHARD ZECKHAUSER * \\ Harvard University, MA, USA
}

\begin{abstract}
Behavioural economic research has established that defaults, one form of nudge, powerfully influence choices. In most policy contexts, all individuals receive the same nudge. We present a model that analyses the optimal universal nudge for a situation in which individuals differ in their preferences and hence should make different choices and may incur a cost for resisting a nudge. Our empirical focus is on terminated choosers (TCs), individuals whose prior choices become no longer available. Specifically, we examine the power of defaults on individuals who had enrolled in Medicare Advantage plans with drug coverage and whose plans were then discontinued. Currently, if these TCs fail to actively choose another Medicare Advantage plan, they are defaulted into traditional fee-for-service Medicare (TM) without drug coverage. Overall, the rate of transition of TCs into TM is low, implying that original preferences and status quo bias overpower the default. Increasing numbers of Americans are choosing plans in health insurance exchange settings such as Medicare, the Affordable Care Act and private exchanges. Plan exits and large numbers of TCs are inevitable, along with other forms of turmoil. Any guidance and defaults provided for TCs should factor in their past revealed preferences.
\end{abstract}

Submitted 30 November 2016; accepted 16 January 2017

\section{Introduction}

The Patient Protection and Affordable Care Act (ACA) of 2010 established state and federal insurance marketplaces. Its twin objectives were to expand access to affordable, high-quality health insurance and to foster a competitive 
marketplace for health insurance. Since the ACA's implementation, health insurance markets for non-elderly individuals have experienced dramatic changes, such as in the range of plan offerings, in plan affordability and in the impact of competition (see Gabel et al., 2014; Dafny et al., 2015a, $2015 b)$. Product entry and exit are natural events in any dynamic marketplace. In some stable markets (e.g. pension bond fund markets), fluctuation of product offerings may be minimal; however, in health insurance marketplaces, which rely at least in part on public financing and regulation, far greater change occurs.

Plan terminations have become a salient characteristic of ACA exchanges (Cox et al., 2015; Cox \& Semanskee, 2016). Plan terminations stem from several sources. For example, in 2016, 12 of the 23 non-profit state-level health care cooperatives ('co-ops'), which together insured more than 700,000 individuals (Armour, 2016) and had, in some marketplaces, a significant share of the market ( $40 \%$ market share in Colorado), exited their marketplaces (King, 2015). United Healthcare and Aetna, two of the largest national health insurers in the US, announced, prior to the 2016 presidential election, their plans to exit marketplaces in 2017 and thereby drop up to 1.5 million enrolled individuals. Those terminations received significant national media coverage and generated considerable political controversy (Cox \& Semanskee, 2016; Pear, 2016). At the time of this writing (January 2017), it is impossible to predict the future of the ACA marketplaces under President Trump and a Republican Congress. But one can confidently predict that, whatever the future, there will be large numbers of individuals whose current health plans will no longer be available.

Despite such earthquakes striking health insurance markets, to our knowledge there has been no examination of the health insurance choices made by enrolees after their chosen insurance plans become unavailable. We label these individuals 'terminated choosers' (TCs). This lack of attention to TCs contrasts sharply with the vast literature on initial choice in public and private health insurance exchange settings. We raise several important questions regarding TCs, people who enrolled in health insurance in a prior period. Following their plans' terminations, will the TCs enrol again, and where? If not, what will happen to them? How does the architecture of the insurance exchanges affect these outcomes and the TCs' welfare?

This paper examines the influence on the eventual plan enrolment outcomes for TCs of a critical aspect of marketplace choice architecture - the TCs' default option. In any decision-making context, the 'default option' is a form of nudge; it is the selection that will be made automatically if an individual fails to make an active choice. In most policy contexts, all individuals receive the same nudge. Following notice of plan termination from a health insurance 
marketplace, enrolees can actively select a new insurance plan during the subsequent open enrolment period. However, a TC who fails to choose a new plan faces a default; that default might involve automatic enrolment in a selected plan, random assignment to one of a group of plans or sudden membership in the ranks of the uninsured.

Research has established the power of defaults to strongly influence outcomes in a range of decisions, from savings and investments to organ donations (Madrian \& Shea, 2001; Johnson \& Goldstein, 2003; Beshears et al., 2009). However, these studies focus overwhelmingly on how defaults affect the decisions of individuals who are selecting options for the first time, individuals whom we label original choosers. TCs represent a different set of clients because they have already actively selected an option. There are three oftmentioned explanations for the power of defaults: (1) the presence of anxiety (Camerer et al., 2005; Frank, 2007); (2) the perception that the default is endorsed by authorities (such as financial planners, personnel officers and policy-makers) who 'know what is best for us' (Goldstein et al., 2008); and (3) the view that the default is the status quo, implying that any alternative could be a significant and regrettable error of commission (Samuelson \& Zeckhauser, 1988). These explanations may apply less forcefully to TCs. Whether defaults are sufficiently powerful to influence strongly the choices of TCs is unknown. Moreover, very little is known about the optimal form of nudge for TCs and whether and how it differs from that for original choosers.

Understanding the choices made by TCs in health insurance marketplaces is important for three reasons. First, health insurance is increasingly offered in market-like settings (Medicare Advantage [MA], Medicare Part D, ACA marketplaces, private exchanges, etc.) in which many health insurance plans terminate, implying that the future enrolment of TCs is an important policy issue. Second, unlike original choosers, TCs have revealed information about their health insurance plan preferences through their prior selections. When defaults differ significantly from these prior choices, TCs are tugged by two competing sets of behavioural tendencies: those tendencies linked to defaults and those associated with the combination of persistent preferences and status quo bias. Greater understanding of the choices TCs make under these circumstances can improve our understanding of other consumers' choices, in health insurance marketplaces and elsewhere. Third, public health insurance marketplaces often establish defaults for enrolees in terminated health plans. It is important to understand the influence exerted on TCs by defaults and, by extension, how to choose appropriate defaults to maximise the welfare of TCs or, alternatively, some combination of TC welfare and societal resources. 
To address these questions, this paper first presents a model that analyses the optimal default nudge for situations in which individuals differ in their preferences and hence in which they should make different choices and in which they incur a cost for resisting a nudge. We then analyse a group of TCs in a health insurance exchange setting: the clients of MA health insurance plans that are cancelled.

MA plans are private health plans in which beneficiaries can enrol in lieu of traditional, fee-for-service (FFS) Medicare (TM), either when they become eligible for Medicare (typically, at age 65) or subsequently during annual openenrolment periods. Although this is a different population from the one that enrols in ACA marketplaces, these beneficiaries, like ACA beneficiaries, face a choice among a set of regulated plans offered at the local level, such as a county. Similarly, the plans for both MA and ACA beneficiaries vary in benefit design, generosity and physician networks. Also, like non-group health plans, MA plans sometimes terminate either because they do not meet some new regulatory standard or because the health insurer chooses to stop offering them, usually due to predicted losses. Then, the plans' enrolees are terminated.

If TCs from MA plans do not actively elect other MA plans, they are defaulted into FFS TM. One might expect defaults to affect powerfully the choices of TCs because insurance choices involve both uncertainty and high stakes, two conditions that have been shown to intensify errors in decisionmaking (Frank, 2007). However, this study observes TCs who at one point chose MA rather than enrol in TM, which was also the default when they made their original choices. This choice actively signals the persistence of their preferences for a benefits package that differs significantly from that of FFS TM and demonstrates their ability to overcome a default to make an active choice. Moreover, status quo bias - the tendency of individuals to continue with a current choice rather than switch - also creates a force that counteracts the influence of the default. In sum, the expected outcome for TCs from MA is unclear when the default opposes revealed preferences and status quo bias.

This paper exploits a natural experiment. Due to legislated changes in plan payment and regulation passed in 2003, large numbers of plans exited the MA programme at uneven rates across the US from 2006 through 2010. This caused large numbers of beneficiaries to become TCs. For this class of individuals, we examine the competing forces of preferences, status quo bias and a default that nudges individuals away from the alternative they had actively chosen in a prior period.

This paper proceeds as follows. We first discuss behavioural economic theory and the general literature on health plan choice, default effects and 
other competing forces. We then present a model of the optimal nudge when individual preferences vary. We next turn to describe the study context, data and methods used in this paper and then present the results. The final two sections of the paper discuss the findings and conclude.

\section{Health plan selection and frictions: theory and evidence}

In the implicit neoclassical model of consumer health insurance plan selection, consumers will assess the attributes of each health plan, including benefit coverage and limits, provider network, health plan quality and total cost (premium plus out-of-pocket cost as a function of expenditures). They will then select their best alternative. While consumers cannot know their future health care needs with any certainty, they have prior beliefs about the distributions of those needs and the costs of treatment under various health plans. Consumers are assumed to understand the relative importance of a health plan's attributes and to weigh them rationally according to their own best interests. Implicitly, they will use a multi-attribute utility function (Keeney \& Raiffa, 1976). Thus, the plans they choose will maximise their expected utility over the potential states of the world. A few advanced consumers will compute expected utility using a benefit-cost approach. They will enrol in the health plan where their expected net benefit, defined as expected benefit across potential states of the world less expected costs across potential states of the world, is greatest. Everyday consumers will intuitively and roughly weigh the advantages and disadvantages of alternative plans.

At regular intervals, consumers will re-evaluate their plan choices in response to changes in plan attributes and their own health status; they will switch plans if better alternatives become available. Under this model, consumers' choices of plans provide information about their preferences among health insurance plans. For example, plan choices based on the preferences of sicker individuals for more complete coverage drive adverse selection, with important consequences for health insurance markets (Arrow, 1963; Cutler \& Reber, 1998).

However, a substantial theoretical and empirical literature finds that consumers frequently behave contrary to this model of health insurance choice. This suggests in turn that some of the model's key underlying assumptions are not satisfied. One important deviation is that consumers have been shown to be strongly influenced by defaults, often as a result of inertia. Moreover, such passive acceptance may not reflect conscious or meaningful choices. Rather, it may be the product of other forces, such as procrastination (Beshears et al., 2008). Seminal articles find evidence of a powerful default effect in the highly consequential area of financial planning and savings decisions 
(Madrian \& Shea, 2001) and in organ donation decisions (Johnson \& Goldstein, 2003).

The well-documented power of defaults underlies the 'nudge approach' to improving individuals' outcomes, where choice architecture is designed with the knowledge that behavioural decisions are likely to lead to personally suboptimal choices (Thaler \& Sunstein, 2009). Nudges can take a great variety of forms. By requiring reading of a passage or presenting an image before a choice is made, a nudge might cause an individual to behave in a more moral, more generous or more long-term fashion. Commercial entities frequently use such priming nudges to get consumers to focus on particularly appealing features of their products. If decisions are of particular but often overlooked importance, there might be a spotlight nudge, requiring individuals to review material or participate in a conversation before making a choice. Requiring an individual to make an active choice is a mild form of spotlighting.

Nudge architects express all sorts of motives when seeking to influence the decisions of others. Some are purely self-interested: I will be better off if I can get you to choose B rather than A. Some are purely paternalistic: choice B is better for you, but you are more likely to choose A absent my nudge. Many nudges are designed to secure socially superior outcomes when externalities are important. Nudges to conserve energy or return aluminium cans fall into this category. Some nudges push towards one choice, but spotlight nudges are often designed merely to get individuals to choose more wisely for themselves.

Defaults are a widely employed form of nudge. For example, in an effort to get individuals to save more for retirement, companies structure retirement benefits so that employees are defaulted into automatic savings plans. When this happens, the vast majority simply remain enrolled. Actions by a few to escape from a default are perceived to be implicit evidence of true preferences.

Status quo bias, which describes disproportionate adherence to previous choices, is another force observed to interfere with the assumptions in our simple choice model. Status quo bias was first identified as affecting health insurance choices in a study of enrolees in employer-sponsored health plans (Samuelson \& Zeckhauser, 1988). Such persistence with prior choices may reflect a quasi-rational reliance on an informal assessment of search and transition costs combined with uncertainty about alternative options. Or such persistence may simply reflect that options change slowly and that people's preferences remain fairly consistent. However, these rationalisations for persistence may not apply in many circumstances. Status quo bias also has the potential to lead people away from rational decision processes. Thus, individuals may give weight to sunk costs and use current decisions as means to justify past choices. They may suffer an endowment effect, in which something 
already possessed takes on an exaggerated value. They may seek to avoid regret; sticking with their initial choice helps them to avoid learning that this choice was poor. They may weight errors of commission (switching plans when they should not) far more than errors of omission (failing to switch when they should) (Samuelson \& Zeckhauser, 1988).

In health insurance marketplaces, TCs have already made a prior choice. When that choice differs substantially from the default, a tug of war ensues for TCs. Tugging on one side is the combination of status quo bias and the persistence of the individuals' original revealed preferences for their health plans; tugging on the other side is the default - that is, the nudge. The outcome is a matter of both theoretical and policy interest. Moreover, a default that goes against an individual's deliberate past choice is more a shove than a nudge. Unless it reflects strong externalities or counteracts the individual's severe biases, it will hurt, not improve welfare. We now move from the specific to the general and present a stylised model of an optimal nudge.

\section{An optimal nudge when preferences vary}

The central question for the virtuous nudger who is seeking to maximise expected welfare while taking both direct individual utilities and societal resources into account is whether to nudge and, if so, what magnitude of nudge should be used in what direction. Posit that nudges must be general; they are directed at the general society and cannot be tailored to specific individuals. Thus, the nudger may be the government choosing a default between TM and MA or a commercial firm trying to nudge people on its product offerings.

For expositional ease, in the following discussion, the socially concerned nudger is taken to be male; the nudgee female.

\section{Preferences}

Each individual has a preference for one of two alternatives, A and B. Her preference ranges on a scale from -1 to 1 . At 1 , she strongly prefers $A$; at -1 , she strongly prefers $\mathrm{B}$. Thus, -0.2 would indicate a mild preference for $\mathrm{B}$. Denote the preference value by $p$.

\section{Nudges}

A nudge pushes an individual towards one choice or the other. A nudge is calibrated on the same scale. Thus, 1 is a strong nudge towards $A ;-1$ is a strong nudge towards B. Denote the nudge value by $n$. 


\section{Susceptibility}

Individuals are more or less susceptible to nudges. The opposite of susceptibility is resistance. Susceptibility is measured from 0 to 1 . This gives the weight to be placed on the nudge versus the preference. Denote the susceptibility value by $s$.

The choice value, $\mathrm{C}$, is given by equation (1):

$$
\mathrm{C}=p(1-s)+n s
$$

Thus, if $s$ is small, preference plays the predominant role; if $s$ is large, $n$ plays a major role. If $\mathrm{C}$ is positive, then the individual picks $\mathrm{A}$; if $\mathrm{C}$ is negative, she picks $\mathrm{B}$. In a more elaborate model, an error term would be added to $\mathrm{C}$ to represent, for example, behavioural factors.

\section{Distributions in the population}

Individuals differ in their preferences and their susceptibilities to nudges. For expositional ease, assume independence on these two variables, though in real life this will often not be the case.

The distribution of preferences is $f(p)$. The distribution of susceptibilities is $g(s)$.

\section{Determining the optimal nudge}

For expositional ease, assume that the individual's preference is for A, but the nudger wishes to push her towards B. There are two prime cases to consider. Case I occurs when there is straight paternalism. Thus, the government may find that people tend to eat unhealthy product A rather than healthier product B. Representative examples would be requiring restaurants to publish their calorie counts, imposing a tax on sugar or prohibiting the sale of soft drinks in schools.

Case II occurs when the nudger has a personal interest in the outcome, quite apart from the preferences of the individual. Thus, it might be a commercial company trying to increase profits or the government trying to shuttle individuals to a health plan that is less expensive for it to provide. Under Case II, the nudgers may have a further divide depending on who is doing the nudging. Presumably, the commercial company would be interested solely in its profits, though it would take customer satisfaction into account to the extent that it affected long-term profits. The government, presumably, would have dual goals: individual satisfaction as well as government costs. Thus, the government would not wish to have its nudge override strong consumer preferences. Our presentation focuses on the case where the nudger, who is 
seeking to maximise expected welfare, has some interest in catering to consumer preferences.

Some nudges can easily be resisted by individuals. Thus, an individual who has a strong preference for product A may stick with it even if advertising, advisories, or salespersons push her strongly towards B. However, overcoming some nudges may entail an actual cost. This happens frequently with defaults when, for example, the process to overcome the default requires substantial time and effort. Difficulty overcoming a default also occurs when one has no idea of how to do so or because the time to do so is far in the future so people do not remember to avoid being defaulted. (Introductory subscriptions to a magazine, which renew automatically unless you call to cancel, represent a prime example of this latter case.) The costs involved in overcoming a default nudge represent deadweight losses.

Consider now the nudger who seeks the optimal nudge, $n^{*}$, to maximise the expected welfare of nudges or that welfare minus social costs. For this illustration, it will be the government, which knows the $f(p)$ and $g(s)$. The government also knows that there is an unrecognised loss of $k$ for every individual who chooses A. Note that $k$ may arise because individuals incur a health cost they underestimate or because the government incurs a financial cost if $\mathrm{A}$ is chosen rather than $\mathrm{B}$ and individuals only pay that cost indirectly through taxes. Finally, there is a deadweight loss of $d$ for every individual who is subjected to the nudge but still chooses A. Thus, $d$ is the cost of overcoming the nudge. Both $k$ and $d$ are calibrated in the same units as $p$. The government, as stated, would like to maximise expected net benefits.

To reiterate, an individual will choose $\mathrm{A}$ if her $\mathrm{C}$ value, $\mathrm{C}=p(1-s)+n s$, is strictly positive. (Assume that indifferent people, $\mathrm{C}=0$, follow the nudge.)

Total welfare is given by equation (2):

$$
\int_{s}\left\{\int_{C \geq 0}(p-k-d) f(p) d p+\int_{C<0}(-p) f(p) d p\right\} g(s) d s
$$

Thus, the government will pick $n^{*}$ to maximise equation (2), the expected payoff to a randomly chosen individual.

Fuller presentations will examine how $n^{*}$ changes depending on $f(p), g(s)$ and the values of $k$ and $d$, etc. For example, if $f(p)$ has considerable density at high values - that is, many people strongly like $\mathrm{A}-g(s)$ takes on mostly modest values; and if $d$ is consequential, then a strong nudge, indeed any nudge, may diminish welfare. This is because a large fraction of the population will overcome the nudge and thus incur consequential cost $d$.

Many additional factors would enter an optimal nudge model. For example, it would seem plausible, of course, that the cost of overcoming a nudge would depend on the magnitude of the nudge, that $d$ would be an increasing function 
of both $n$ and $|-n|$. If so, as $d$ increases, the optimal nudge would diminish. Two factors lead to this result. First, as $d$ increases, the benefits of switching the marginal individual diminish. Second, the cost to those not switching increases. A reduction in the magnitude of the nudge is beneficial on both grounds.

The optimal nudge will likely change over time, since the distributions of preferences and susceptibilities will change. Suppose that one nudges a population once. Some people follow the nudge, others do not. Presumably, nudge followers are disproportionately individuals with low values of $p$, though some with higher values of $p$ but also high values of $s$ will also be nudged.

Of course, if nothing changes, a second nudge of the same value would have no effect. This would not be the case if individuals make errors in computing C. For example, an individual who usually would have switched might not have done so the first time. Alternatively, $p$ and $s$ might drift around a bit, perhaps following a random walk, so a second-round nudge would change behaviour. Even in light of these possibilities, we would still expect those who resisted the nudge initially to be disproportionately high in $p$. Under reasonable regularity conditions, this high $p$ result for initial resisters would imply that, for this group, the optimal nudge would be weaker the second time around. A greater percentage of the folks who would be subject to it would appropriately stick with choice A. The converse also applies. In a situation where people have to choose a second time, the optimal nudge for those who initially succumbed would be increased.

We now turn to apply this broad framework for nudges to the particular empirical problem of defaults for TCs in health insurance markets. We examine the results of a nudge of TCs from MA who encounter a default into TM, where TCs can only overcome that nudge if they make an active choice back into MA. We first describe MA in more detail and then examine that problem empirically.

\section{Study context, data and methods}

\section{Medicare Advantage}

One of the most consequential choices an elderly person can make is whether to enrol in TM, which provides FFS health insurance, or in an MA plan, which gives beneficiaries a choice among private health plans that offer benefits that are at least actuarially equivalent to TM. The Medicare enrolment process typically favours TM, as evidenced by the way beneficiaries are defaulted into the hospital insurance component of the programme (known as Part A) and by the way information is presented in the Medicare and You package. Unlike TM, most MA plans are managed-care plans in which 
beneficiaries accept access to a limited physician network and also accept having their care managed (through prior authorisation and gatekeeping) in exchange for more generous benefits. However, some MA plans are private FFS plans. MA plans can offer prescription drug coverage through Medicare Part D (MA-PD plans) or not (MA-only plans). Many additional details on the MA programme and the history of plan availability and enrolment are contained in Sinaiko and Zeckhauser (2016).

From 2008 forwards, the total number of MA plans decreased, for a few reasons. The ACA of 2010 reduced payments to MA plans relative to TM. This legislative measure led some health maintenance organisation (HMO) and preferred provider organisation (PPO) plans to exit the market (Afendulis et al., 2012). The anticipated payment reductions, along with provisions in the Medicare Improvements for Patients and Providers Act (MIPPA) of 2008 that imposed a network requirement on private FFS (PFFS) plans, made such plans less attractive; therefore, fewer were offered. Some counties experienced much greater rates of MA plan exits than others, although, in contrast to the earlier era in the late 1990s, beneficiaries in all counties continued to have access to at least one MA plan of each plan type from 2007 to 2010 (MedPAC, 2011). Importantly for the purposes of our study, these plan exits were not likely to have been driven by demand-side behaviour (e.g. by lack of beneficiary demand for MA). In fact, MA enrolment continued to grow steadily through November 2015 (MedPAC, 2016), the latest date available.

\section{Medicare beneficiary plan choice}

A growing body of evidence reveals beneficiary behaviours and characteristics that explain why some Medicare beneficiaries enrol in a plan that is suboptimal for them. A significant example is status quo bias in the Medicare market, which causes some individuals who enrol in MA to remain in the programme over long periods of time. Indeed, only a tiny fraction of enrolees in TM switch into MA (Sinaiko et al., 2013; Afendulis et al., 2014). McWilliams et al. (2011) find evidence consistent with 'choice overload', showing that rates of enrolment in MA increased as plan choices increased up to 15 , then plateaued with 16-30 plan choices and then declined when beneficiaries had more than 30 choices available. In the MA-PD programme, a beneficiary chooses among prescription drug plans in an exchange setting. Money-wasting choices in Part D, defined as plans that for a given level of risk do not roughly minimise the sum of a beneficiary's premiums and out-of-pocket costs, have been observed in significant numbers among all enrolees and among TCs specifically (Abaluck \& Gruber, 2011, 2013; Kuye et al., 2013). Low rates of enrolment in Part D by eligibles who would receive the low 
income subsidy, making their drug coverage essentially free, represents an extreme money-wasting choice (Kuye et al., 2013).

The evidence suggests that TCs are among those making the most effective choices in the Medicare programme. First, TCs consciously chose to enrol in MA at the outset rather than accept the TM default, thereby demonstrating their preference for receiving health insurance through an MA plan. Second, a higher proportion of MA clients rather than TM clients enrol in MA-PD, which offers prescription drug coverage at heavily subsidised rates and thus reflects an effective choice. Given these facts, we would expect TCs to be less susceptible than most to a default into TM.

\section{Data}

We obtained data from the Centers for Medicare and Medicaid Services (CMS) on the entire population of eligible elderly (age 65+) Medicare beneficiaries in the United States who had chosen to enrol in an MA plan that included prescription drug coverage (known as an MA-PD plan) for the years 20062011. Henceforth, for ease of exposition, when we refer to MA or MA plans or clients, we mean MA-PD enrolees.

We excluded beneficiaries who became eligible for Medicare due to disability, those dually eligible for Medicaid, the long-term institutionalised and those enrolled with an insurer outside of their county of residence. We also excluded enrolees in MA employer plans and special needs plans because these beneficiaries face significantly different enrolment choices and incentives. Finally, to focus the analysis on the plan choices and outcomes on locales with robust MA marketplaces, we restricted the analysis to beneficiaries who lived in the 200 US counties with the largest elderly populations and who also were enrolled in the three most common types of MA contracts: HMOs, PPOs and PFFS. This sample included 17,651,389 elderly-person-year observations. The data included information on beneficiaries' dates of birth, genders, races (black or non-black), zip codes of residence, the MA contracts in which they were enrolled and whether they continued to be enrolled in MA or switched to TM in each month of the study period.

Generally, insurers contract with Medicare to offer a specific type of plan (HMO, PPO or PFFS) in a county, but many insurers offer multiple plans with different names and variable benefits under each contract. Our data included identifiable contract-level, but not plan-level, enrolment information for each beneficiary. The data also included an encrypted plan-level ID for each beneficiary that, importantly for this study, allowed us to link to information on market-level plan changes at the county level (such as consolidations, mergers, exits or no change). Because we did not have information on the 
default options for beneficiaries whose MA plans went through a merger or consolidation, we dropped these beneficiaries $(2.4 \%$ of observations) from our analysis. Our final study sample, following this exclusion, included 17,226,866 person-year observations.

\section{Cohorts}

We analysed the characteristics and transitions of TCs over three pairs of years: 2006-2007, 2009-2010 and 2010-2011. We did not examine transitions in 2007-2008 or 2008-2009 because very few MA contracts terminated in those intermediate years; as a consequence, they provided too few TCs to study. Due to data limitations, we could not observe the types of MA contracts in which voluntary switchers and TCs enrolled in 2011; neither could we examine the choices across plans for beneficiaries who remained in MA in 2011. Therefore, we only examined transitions from MA to TM during the 2010-2011 period, both by TCs and by voluntary switchers, a group defined two paragraphs below.

Our study group of TCs included all beneficiaries in our sample who were enrolled in a plan within an MA-PD contract that was offered in their county of residence in the first year of the period but that was no longer offered in the second year. We conducted this analysis at the contract level for two reasons. First, contract exits often leave beneficiaries without a substitute nearly identical to the terminated plan, which is not the case with plan exits. Second, we know the default for these clients, namely enrolment in TM.

We analysed the choices of two other types of MA beneficiaries in our sample: voluntary switchers and stayers. Voluntary switchers are those who chose to either switch to a new MA contract or switch into TM, although their prior MA contract continued to be available had they wanted to stay enrolled in it. Stayers are beneficiaries who did not act during open enrolment and, therefore, by choice or by inaction, were re-enrolled the following year in their existing plans. Both voluntary switchers and stayers faced circumstances different from those of TCs, given that TCs had no choice but to switch plans.

\section{Statistical analyses}

TCs differ from voluntary switchers and from stayers because TCs, but for the termination of their plan, would have included both stayers and voluntary switchers. Given the termination, we cannot distinguish between these two types in enrolment claims data. Comparing TCs to either group alone would be a biased comparison.

In order best to identify appropriate comparisons for the choices of TCs and to bring balance to our terminated and comparison populations, we used a 
weighting system that has a propensity score approach (Hirano \& Imbens, 2001; Kurth et al., 2006). This approach accounts for observable differences between TCs and non-TCs (including both voluntary switchers and stayers) and thus brings the non-TC population into balance with the TCs. We then analysed differences in plan outcomes between this weighted comparison group of non-TCs and TCs.

This approach first employed a logit model to estimate the propensity (likelihood) for being a TC on the basis of age, gender, race (black or not) and county. We controlled for county because plan payment rates are set at the county level and thus could affect a health plan's likelihood for withdrawal and a beneficiary's probability of becoming a TC. Moreover, because all residents within a county face the same plan choices, our results were not driven by differences in underlying plan choice sets facing TCs and non-TCs. To account for changes in payments and differences in preferences for insurance plan types, models were run separately by year and MA plan type (HMO, PPO or PFFS). We applied the coefficients from these models to the data in order to estimate the probability, $p$, that each beneficiary in a non-terminated contract would be a TC. We then generated a set of weights where each TC was assigned a weight equal to 1 and non-TCs were assigned a weight of $(p / 1-p)$ (Hirano $\&$ Imbens, 2001; Kurth et al., 2006). To avoid a loss in efficiency, we restricted the 2009 PFFS models to include only counties where there were at least as many nonTCs as TCs. The weighted distributions of characteristics of TCs and nonTCs were identical; therefore, weighted analyses were adjusted for potential confounding due to the individual characteristics included in the propensity score models. This methodology has previously been used to analyse the impact of health insurance on health care utilisation and on health care spending (see McWilliams et al., 2007; Zhang et al., 2009).

We compared weighted rates of enrolment into TM and into MA overall. Analysing beneficiaries who remained in MA, we compared rates of enrolment across types of MA plans (MA-HMO, MA-PPO and MA-PFFS). Statistical significance was assessed using Pearson's chi-square test. We also compared differences in rates of enrolment in Part D plans among beneficiaries who switched into TM.

\section{Results}

\section{Statistical analyses}

Over the period 2006-2010, nearly 233,000 beneficiaries in MA plans became TCs. TCs were similar in age, gender and race to both voluntary switchers and stayers, but were much more likely to have been enrolled in their MA contracts 
for a shorter duration of one year or less (Table 1). The vast majority of the MA contract exits examined occurred in 2006, 2009 and 2010. For additional detail on rates of beneficiaries' switching out of MA plans and for descriptions of transitions to other MA plans or to TM, see Sinaiko and Zeckhauser (2016).

To draw appropriate inferences about the impacts of default policies and the effects of terminated plans, we present results on plan enrolment outcomes of TCs versus those of a sample of non-TCs that includes both voluntary switchers and stayers, where members of that sample were weighted according to their likelihood of being in a terminated plan, thereby creating balance between the two groups. TCs in our pooled sample were more likely to transition to TM than were non-TCs $(11.1 \%$ vs $2.6 \%, \mathrm{p}<0.001)$ (Table 2$)$. This pattern holds both among TCs who were originally enrolled in HMOs and those originally enrolled in MA-PFFS plans. TCs were three times more likely than non-TCs to move to TM from MA-HMO contracts in 2006, 12 times more likely to move to TM from MA-HMO contracts in 2009 and twice as likely to move to TM from MA-PFFS contracts in 2009.

Multiple forces could contribute to these dramatic disparities. One possibility is that status quo bias among individuals whose plans survived led them to continue with their plans. A second is that some TCs were influenced by the default into TM, although TM may or may not have been their second choice. We incline to the principal explanation of status quo bias on the part of the non-TCs because that group's members only switched to TM $2.6 \%$ of the time. The switching percentage of TCs into TM was $11.1 \%$, implying that the default was consequential but hardly determinative.

\section{Further analysis of quality of choices and susceptibility to nudges}

TCs who transitioned from MA into TM were a distinct minority. No doubt, some of these transitions were voluntary, but some may have been influenced by the default into TM. If so, this should be reflected in a lesser likelihood that TCs going to TM as opposed to MA would be enrolled in a plan with prescription drug coverage. That is because, prior to their plan terminations, all TCs in our sample had actively selected a MA plan that included a prescription drug plan. If consciously considering their plan choice, they would presumably choose a plan with prescription drug coverage again, particularly given the actuarial favourability of Part D coverage. TCs going to MA made a conscious choice. Those going to TM may have merely been defaulted. Hence, the latter are more likely not to have a prescription drug plan, as that is the default. We compared the rates of enrolment in a Part D plan among TCs (Table 3). Table 3 shows that among all TCs, those moving to TM were dramatically (and significantly) more likely to fail to enrol in a Part $\mathrm{D}$ plan than were their peers who 
Table 1. Characteristics of stayers versus terminated choosers versus voluntary switchers: Medicare Part D enrolees in the 200 largest counties in the US, 2006-2010.

\begin{tabular}{lccc}
\hline \hline & Stayers & Terminated choosers & Voluntary switchers \\
\hline Person-years $(n)$ & $15,590,641$ & 232,538 & $1,403,687$ \\
Female & $58.4 \%$ & $57.3 \%$ & $55.8 \%$ \\
Black (vs non-black) & $7.9 \%$ & $7.7 \%$ & $9.1 \%$ \\
Age & & & \\
$65-69$ & $27.9 \%$ & $35.3 \%$ & $31.8 \%$ \\
$70-74$ & $25.7 \%$ & $25.3 \%$ & $25.1 \%$ \\
$75-79$ & $21.9 \%$ & $18.5 \%$ & $19.9 \%$ \\
$80-84$ & $14.9 \%$ & $12.4 \%$ & $13.5 \%$ \\
$85+$ & $9.7 \%$ & $8.6 \%$ & $9.8 \%$ \\
Years enrolled in plan (prior & to 3 ittch) & & \\
$<1$ & $13.1 \%$ & $40.8 \%$ & $27.0 \%$ \\
1 & $13.5 \%$ & $18.4 \%$ & $19.1 \%$ \\
2 & $10.6 \%$ & $12.4 \%$ & $14.5 \%$ \\
$3+$ & $62.7 \%$ & $28.5 \%$ & $38.9 \%$ \\
Expected OOPC & $\$ 284$ & $\$ 350$ & $\$ 279$ \\
Premium & a & $\$ 171$ & $\$ 132$ \\
Base year & $\$ 135$ & & \\
2006 & & 29,283 & 194,292 \\
2007 & $2,684,837$ & 3184 & 193,470 \\
2008 & $2,888,710$ & 1745 & 207,787 \\
2009 & $3,217,796$ & 57,591 & 388,048 \\
2010 & $3,280,679$ & 140,735 & 420,090 \\
\hline \hline
\end{tabular}

Sample includes beneficiaries who gained eligibility and were not disabled. Excludes beneficiaries in employer-sponsored plans and non-health maintenance organisation, preferred provider organisation and private fee-for-service plans. Excludes beneficiaries in contracts that experienced a merger or consolidation.

${ }^{a}$ Excludes 2006 (data not available).

Stayers $=$ did not switch out of Medicare Part D contract.

Terminated choosers = switched out of Medicare Part D contract not offered in county in subsequent year.

Voluntary switchers = switched out of Medicare Part D contract offered in county in subsequent year.

OOPC $=$ out-of-pocket cost.

Source: Authors' analysis of Medicare enrolment data.

actively chose to stay in MA (20.6\% vs $1.7 \%)$. Table 3 also shows the population of TCs who transitioned to TM. Beneficiaries who were male were slightly more likely to fail to enrol in Part D than were women $(24.0 \%$ vs $19.2 \%, \mathrm{p}<0.001)$; beneficiaries who were black versus non-black were much less likely to enrol $(38.7 \%$ vs $20.2 \%$, p < 0.001$)$. Failure to enrol in a 
Table 2. Enrolment outcomes for terminated choosers versus weighted comparison group.

\begin{tabular}{|c|c|c|c|}
\hline & & $\begin{array}{l}\text { Terminated } \\
\text { choosers }\end{array}$ & $\begin{array}{c}\text { Weighted } \\
\text { comparison group }\end{array}$ \\
\hline & Enrolment in next year & & \\
\hline \multirow{4}{*}{ Study sample overall } & $\mathrm{TM}$ & $11.1 \%$ & $2.6 \%$ \\
\hline & MA-HMO & $46.4 \%$ & $83.8 \%$ \\
\hline & MA-PPO & $12.8 \%$ & $2.5 \%$ \\
\hline & MA-PFFS & $29.5 \%$ & $11.0 \%$ \\
\hline \multicolumn{4}{|c|}{ Stratified by year and plan type } \\
\hline & Enrolment in 2007 & & \\
\hline \multirow{5}{*}{ MA-HMO in 2006} & $\mathrm{TM}$ & $5.2 \%$ & $1.3 \%$ \\
\hline & MA-HMO & $58.2 \%$ & $96.8 \%$ \\
\hline & MA-PPO & $1.3 \%$ & $0.2 \%$ \\
\hline & MA-PFFS & $35.2 \%$ & $1.6 \%$ \\
\hline & Enrolment in 2010 & & \\
\hline \multirow{5}{*}{ MA-HMO in 2009} & $\mathrm{TM}$ & $15.4 \%$ & $1.3 \%$ \\
\hline & MA-HMO & $52.4 \%$ & $96.3 \%$ \\
\hline & MA-PPO & $18.5 \%$ & $1.8 \%$ \\
\hline & MA-PFFS & $13.3 \%$ & $0.6 \%$ \\
\hline & Enrolment in 2010 & & \\
\hline & $\mathrm{TM}$ & $17.5 \%$ & $7.9 \%$ \\
\hline \multirow{3}{*}{ MA-PFFS in 2009} & MA-HMO & $30.5 \%$ & $15.2 \%$ \\
\hline & MA-PPO & $25.8 \%$ & $12.0 \%$ \\
\hline & MA-PFFS & $26.1 \%$ & $65.0 \%$ \\
\hline
\end{tabular}

Study sample includes terminated choosers (enrolees in terminated HMO plans in 2006 or 2009 or in terminated PFFS plans in 2009) and comparison group of non-terminated choosers. All differences in distribution of enrolment across plan types are statistically significant at $p<0.001$.

$\mathrm{HMO}=$ health maintenance organisation; $\mathrm{MA}=$ Medicare Advantage; PFFS = private fee-for-service; $\mathrm{PPO}=$ preferred provider organisation; $\mathrm{TM}=$ traditional Medicare .

Part D plan decreased moderately with advancing age and with increasing median household income in the beneficiary's zip code.

\section{Discussion}

This study investigated the phenomenon of a policy-imposed default versus the forces promoting consistent choices among TCs in health insurance markets. The evidence shows that the default policy associated with contract terminations in MA had a moderate impact on the transitions of beneficiaries in terminated plans from MA to TM. TCs were more likely to be enrolled in TM in the year following their plan terminations than were non-TCs. However, a very 
Table 3. Susceptibility to nudges: proportion of terminated choosers who did not select a Part D plan.

Did not enrol in Part D (\%)

\begin{tabular}{lr}
\hline All TCs with plan termination in 2009 & \\
TCs who chose a new MA plan & $1.7 \%$ \\
TCs who went into TM & $20.6 \%$ \\
TCs with plan termination in 2009 or 2010 who went into TM & \\
Male & $24.0 \%$ \\
Female & $19.2 \%$ \\
Black & $38.7 \%$ \\
Non-black & $20.2 \%$ \\
Age group & \\
$65-69$ & $23.8 \%$ \\
$70-74$ & $20.7 \%$ \\
$75-79$ & $20.6 \%$ \\
$80-84$ & $19.8 \%$ \\
$85+$ & $16.4 \%$ \\
Distribution of median HH income in zip code & \\
First quartile (lowest median HH income) & $24.5 \%$ \\
Second quartile & $20.6 \%$ \\
Third quartile & $20.4 \%$ \\
Fourth quartile (highest median HH income) & $19.2 \%$
\end{tabular}

Predicted enrolment based on logistic regression model controlling for age, gender, race (black or non-black), median HH income in zip code of residence and year (sample size: 44,286).

$\mathrm{HH}=$ household; $\mathrm{MA}=$ Medicare Advantage; $\mathrm{TC}=$ terminated chooser; $\mathrm{TM}=$ traditional Medicare . Source: Authors' analysis of Medicare enrolment data.

large percentage of TCs took specific action to select new MA plans following their initial plan's termination. Their active choices to remain in MA likely stemmed from the same preferences that had been operating when they originally reviewed the available plans and deliberately chose MA. The persistent preferences of these individuals were perhaps reinforced by status quo bias, which has been shown to exist for some combination of rational and irrational reasons among Medicare beneficiaries.

The majority of TCs who transitioned into TM from 2009 to 2010 also showed their ability to make choices contrary to a default. Roughly fourfifths of them took the active step to enrol in the Part D benefit. The remaining fifth of TCs transitioning to TM following their plans' terminations failed to enrol in a Part D plan, an outcome in contrast to their prior selection of an MA plan with Part D, suggesting they were susceptible to the default nudge. Those most susceptible were much more likely to be black and somewhat more likely to be male and younger and to live in a zip code with a lower median household income. The finding that actively choosing Part D increases 
with age is a bit surprising given that ageing is associated with a cognitive decline that inhibits decision-making, which in turn would promote susceptibility to a default. However, working in opposition to this, and presumably prevailing, is the fact that older beneficiaries are likely to need substantially more prescription drugs and thus would benefit more from Part D coverage.

Typically, default rules are used to nudge people away from making errors that might otherwise occur in complex, high-stakes choice environments (e.g. with $401 \mathrm{~K}$ plan enrolment) and where the experts are in relatively widespread agreement on which alternative is superior for them. The terminated MA default nudge studied here differs dramatically from such traditional policy nudges for two reasons. First, there is no evidence that it was actively designed to promote superior choices for individuals. In fact, the lack of automatic enrolment in Part D leaves beneficiaries who accept the default substantially worse off in expectation than they would have been if they had been able to stay in their prior plans. Second, this default pushes individuals towards an option that is quite different from what they had chosen in a prior period. It is more in the nature of a shove than a nudge. These two features of the default, and therefore its implications for consumer welfare, differ from the vast majority of defaults, or more generally nudges, reported in prior literature.

The specified default for TCs in MA is likely in place because it mirrors the default for original choosers in the Medicare programme, which is TM, and it is the most administratively simple to implement. However, the specified default of TCs into TM fails to make use of information about beneficiaries' revealed preferences among plans. A second MA plan is likely to be more similar to the original choice than TM in several consequential ways (covered benefits, cost-sharing requirements, etc.) and hence more likely to be better suited to the client.

\section{Conclusion}

TCs are a special group of choosers. Because of their choices in prior periods, they have revealed very clear information about their preferences. Conclusions derived from the model for optimal defaults and the evidence of the experience of TCs in MA suggest that any guidance and defaults provided for TCs should attend to these revealed preferences. Smart defaults, which take into account individual starting positions, preferences or expected needs, have been suggested as alternatives to the one default for all analysed in this paper (Smith et al., 2009). Smart defaults have begun to be used in other public health insurance programmes (California Department of Health Care Services, 2014) and have been shown to have the potential to achieve large savings for enrolees in MA-PD (Zhang et al., 2015). A version of smart default, in which TCs may be 
automatically enrolled in a new plan (generally the lowest-cost plan of the same product network type) if they do not choose a new plan or opt out of the marketplace, has been introduced in the federally facilitated ACA marketplaces for 2017 (Jost, 2016). Smart defaults in Medicare would add administrative complexity, but they would be feasible. For example, in Medicare, a smart default system could analyse the degree of overlap in physician networks across MA plans in an area. It could then use MA as the default if the overlap reached a certain threshold; below the threshold, the default would be TM. An even more sophisticated algorithm could consider which physicians the individual had previously used and, at a more advanced level still, could even include information about recent diagnoses and the implications for appropriate health care coverage. The success of these default alternatives would be revealed if we observed that relatively few TCs chose against them.

Great policy importance is attached to concerns such as whether TCs in health insurance exchanges select and enrol in new plans and how their responses vary based on default policies and previous insurance status, health status and other characteristics. For 2017, 13.8 million individuals are expected to enrol in health plans through state or federal health insurance marketplaces created under the ACA (Department of Health and Human Services, 2016). Increasing numbers of Americans are choosing plans in other health insurance exchange settings, such as Medicare and private exchanges. Turmoil, plan terminations and large numbers of TCs are inevitable in many of these exchanges. Due to varying preferences for health insurance and varying susceptibility to nudges, the effects of default policies associated with plan terminations on these terminated beneficiaries, as well as the implications for consumer welfare, could vary dramatically. Thus, the interplay among nudge susceptibility, preferences and responses to defaults of all types of beneficiaries has implications for the design of optimal defaults. Understanding that interplay could promote the health of our health insurance arrangements.

\section{Acknowledgements}

The authors gratefully acknowledge funding from the National Institute of Aging through P01 AG032952, The Role of Private Plans in Medicare. We thank Alan Zaslavsky for expert guidance in estimating and implementing propensity score-based weighting. We are grateful to Jeff Souza and Lauren Riedel, who provided excellent programming and research assistance. We thank Joseph Newhouse, Adam Oliver, Joshua Schwarzstein and Cass Sunstein for offering useful suggestions. We are also grateful to numerous participants in the 2014 Conference on Behavioral Economics, Law, and Health Policy at the Petrie-Flom Center at Harvard Law School, to participants in the American Society of 
Health Economists' (ASHEcon) 5th Biennial Conference in Los Angeles, CA, in June 2014 and to participants in the Academy Health 2015 Annual Research Meeting in Minneapolis, MN, who provided helpful suggestions.

\section{References}

Abaluck, J. and J. Gruber (2011), 'Choice Inconsistencies among the Elderly: Evidence from Plan Choice in the Medicare Part D Program', American Economic Review, 101(4): 1180-1210.

Abaluck, J. and J. Gruber (2013), 'Evolving Choice Inconsistencies in Choice of Prescription Drug Insurance', NBER Working Paper 19163 June.

Afendulis, C. C., M. B. Landrum, M. E. Chernew (2012), 'The Impact of the Affordable Care Act on Medicare Advantage Plan Availability and Enrollment', Health Services Research, 47(6): 2339-2352.

Afendulis, C. C., A. D. Sinaiko, R. G. Frank (2014), 'Dominated Choices and Medicare Advantage Enrollment', NBER Working Paper no. 20181.

Armour, S. (2016), 'Republicans Question Viability of Co-Ops', Wall Street Journal (online) [New York, NY] 25 Feb.

Arrow, K. (1963), 'Uncertainty and the Welfare Economics of Medical Care', American Economic Review, 53(5): 941-973.

Beshears, J., J. J. Choi, D. Laibson and B. C. Madrian (2008), 'How Are Preferences Revealed?', Journal of Public Economics, 92(8-9): 1787-94.

Beshears, J., J. J. Choi, D. Laibson and B. C. Madrian (2009), 'The Importance of Default Options for Retirement Savings Options', in Brown, Liebman and Wise, (eds), Social Security Policy in a Changing Environment, Chicago, IL: University of Chicago Press, 167-195.

California Department of Health Care Services (2014), 'Duals Demonstration Memorandum of Understanding (MOU)', www.dhcs.ca.gov/Pages/demoMOU.aspx.

Camerer, C., G. Loewenstein and D. Prelec (2005), 'Neuroeconomics: How Neuroscience can Inform Economics', Journal of Economic Literature, 43(1): 9-64.

Cox, C., G. Claxton, L. Levitt (2015), 'Analysis of Insurer Participation in 2016 Marketplaces', Kaiser Family Foundation Issue Brief. Nov 03, http://kff.org/health-reform/issue-brief/ analysis-of-insurer-participation-in-2016-marketplaces/ (Accessed on Apr 20 2015).

Cox, C. and A. Semanskee (2016), 'Analysis of UnitedHealth Group's Premiums and Participation in ACA Marketplaces', Kaiser Family Foundation Issue Brief. April 18.

Cox, C. and A. Semanskee (2016), 'Preliminary Data on Insurer Exits and Entrants in 2017 Affordable Care Act Marketplaces', Kaiser Family Foundation Data Note. August.

Cutler, D. and S. Reber (1998), 'Paying for Health Insurance: The Trade-off Between Competition and Adverse Selection', Quarterly Journal of Economics, 113(2): 443-466.

Dafny, L., J. Gruber and C. Ody (2015a), 'More Insurers Lower Premiums: Evidence from Initial Pricing in the Health Insurance Marketplaces', American Journal of Health Economics, 1 (1): 53-81.

Dafny, L., I. Hendel and N. Wilson (2015b), 'Narrow Networks on the Health Insurance Exchanges: What Do They Look Like and How Do They Affect Pricing?', American Economic Review, 105(5): 110-114.

Department of Health and Human Services (2016), 'Health Insurance Marketplace Enrollment Projections for 2017', ASPE Issue Brief Assistant Secretary for Planning and Evaluation, October 19. Available at: https://aspe.hhs.gov/sites/default/files/pdf/211056/Enrollment Projections.pdf

Frank, R. G. (2007), 'Behavioral Economics and Health Economics', in P. Diamond and H. Vartiainen (eds), Behavioral Economics and Its Applications, Princeton: Princeton University Press. 
Gabel, J. R., H. Whitmore, S. Stromberg, et al. (2014), 'Analysis Finds No Nationwide Increase in Health Insurance Marketplace Premiums', Commonwealth Fund Blog [blog on the Internet]. Dec 22 [cited 2016 Apr 20]. Available from: http://www.commonwealthfund.org/ publications/blog/2014/dec/zero-inflation-nationwide-for-marketplace-premiums

Goldstein, D. G., E. J. Johnson, A. Herrmann and M. Heitman (2008), 'Nudge Your Customers Toward Better Choices', Harvard Business Review, December: 99-105.

Hirano, K. and G. W. Imbens (2001), 'Estimation of Causal Effects Using Propensity Score Weighting: An Application to Data on Right Heart Catheterization', Health Services and Outcomes Research Methodology, 2:259-278.

Johnson, E. J. and D. G. Goldstein (2003), 'Do Defaults Save Lives?', Science, 302:1338-1339.

Jost, T. (2016), 'Updated Renewal and Discontinuation Notices, Auto-Reenrollment, And Other ACA Developments', Health Affairs Blog September 5; www.healthaffairs.org (accessed December 4, 2016).

Keeney, R. L. and H. Raiffa (1976), Decisions with Multiple Objectives: Preferences and Value Trade-offs, Cambridge [England], New York, N.Y.: Cambridge University Press.

King, R. (2015), 'Colorado to Close Obamacare Co-Op', Washington Examiner (online). October 16.

Kurth, T., A. M. Walker, R. J. Glynn, et al. (2006), 'Results of Multivariable Logistic Regression, Propensity Matching, Propensity Adjustment, and Propensity-based Weighting Under Conditions of Nonuniform Effect', American Journal of Epidemiology, 163:262-270.

Kuye, I. O., R. G. Frank and J. M. McWilliams (2013), 'Cognition and Take-Up of Subsidized Drug Benefits by Medicare Beneficiaries’, JAMA Internal Medicine, doi:10.1001/jamainternmed. 2013.845 .

Madrian, B. C. and D. F. Shea (2001), 'The Power of Suggestion: Inertia in 401(k) Participation and Savings Behavior', Quarterly Journal of Economics, 116:1149-87.

McWilliams, J. M., C. C. Afendulis, T. G. McGuire and B. E. Landon (2011), 'Complex Medicare Advantage Choices May Overwhelm Seniors-Especially Those with Impaired Decision Making', Health Affairs, 30(9): 1786-94.

McWilliams, J. M., E. Meara, A. M. Zaslavsky and J. Z. Ayanian (2007a), 'Use of Health Services By Previously Uninsured Medicare Beneficiaries', New England Journal of Medicine, 357: 14353. PMID: 17625126.

Medicare Payment Advisory Commission (2011), Report to Congress: Medicare Payment Policy. Washington, DC: Medicare Payment Advisory Commission.

Medicare Payment Advisory Commission (2016), Report to Congress: Medicare Payment Policy. Washington, DC: Medicare Payment Advisory Commission.

Pear, R. (2016), 'Aetna to Pull Back From Public Health Care Exchanges', New York Times August 16.

Samuelson, W. and R. Zeckhauser (1988), 'Status Quo Bias in Decision Making', Journal of Risk and Uncertainty, 1: 7-59.

Sinaiko, A. D., C. C. Afendulis and R. G. Frank (2013), 'Enrollment in Medicare Advantage Plans in Miami-Dade County: Evidence of Status Quo Bias?', Inquiry.

Sinaiko, A. D. and R. Zeckhauser (2016), 'Enrollee Choices After Their Health Plans Are Terminated: Default Effects Versus Persistent Preferences', Harvard Kennedy School Working Paper.

Smith, C. N., D. Goldstein and E. J. Johnson (2009), 'Smart Defaults: From Hidden Persuaders to Adaptive Helpers', (Working Paper, INSEAD); available at http://papers.ssrn.com.ezpprod1.hul.harvard.edu/sol3/papers.cfm?abstract_id=1116650

Thaler, R. and C. Sunstein (2009), Nudge: Improving Decisions about Health, Wealth and Happiness, New York, NY: Penguin Books.

Zhang, Y., S. H. Baik and J. P. Newhouse (2015), 'Use of Intelligent Assignment to Medicare Part D Plans for People With Schizophrenia Could Produce Substantial Savings', Health Affairs, 34(3): 455-460.

Zhang, Y., J. M. Donohue, J. R. Lave, G. O'Donnel and J. P. Newhouse (2009), 'The Effect of Medicare Part D on Drug and Medical Spending', New England Journal of Medicine, 361: 52-61. 